\title{
Solar Powered Airlift Pump for Gardening
}

\author{
Kush Samir Hemani \\ B.D. Somani International School \\ Cuffe Parade, Colaba, Mumbai, Maharashtra \\ 400005
}

\begin{abstract}
The objective of this research project was to design a device, which uses an airlift pump powered by solar energy to draw water. Farmers are the main constituents of the primary sector in most countries. Frequently farmers use excessive amounts of water, which not only harms the crops but also depletes the water table. In a world where there is a shortage of water, it is extremely important that we rely on specifically programmed devices that are simple to design, easy to use and are able to water plants in an efficient manner. Extensive use of such devices will help us to save precious water and may help solve the problem of world hunger through adequate farm produce. This concept can be also be applied in hydroponics, a method of growing plants in water, not soil, using mineral nutrient solutions. Due to rapid urbanization in various urban corridors where there is a large demand for fresh food, food can be supplied by hydroponics.
\end{abstract}

Only $1.361 \mathrm{~kW} / \mathrm{m}^{2}$ of the energy released by the sun actually reaches the planet. It is extremely important to make sure that we harness this energy. Solar energy is a renewable resource and using it would for sure help us reduce the global warming and help conserve bio fuels and other scarce resources. The use of solar energy provides flexibility in installation of such devices in places where electricity is not available. [2]

\section{General Terms \\ Solar Power}

\section{Keywords}

Solar, Power, Airlift, Pump, Gardening, Renewable, energy

\section{MOTIVATION FOR THE PROJECT}

I have been associated with project Chirag - (a youth initiative involved in installing solar lights in rural villages in India). It was instrumental in kindling my desire to apply the use solar energy in in other practical aspects of daily life. My first hand exposure to rural India while working with project Chirag made me aware of the problems faced by poor, uneducated and neglected sector of our community. One morning as was returning from my morning run, I saw a gardener watering plants and the amount of water that was being wasted as he carried a pipe of running water from plant to plant (spilling a lot of water, making a mess of the building compound) was quite formidable. [3] Each plant requires adequate amount of water regularly. If water used wisely for gardening a lot water that is wasted due to excess watering of the plants, (which eventually seeps out of the planter) can be avoided. Water around the world is getting depleted and should be treated as a scarce resource. These problems made me give a serious thought and almost immediately, this idea of making a solar pump crossed my mind. Since solar energy is unlimited, and has no impact on climate and is relatively cost effective seemed just perfect to make a device that works on solar power. As against electricity generated by power

\author{
Ravi Mariwala, Ph.D \\ Institute of ChemicalTechnology \\ Nathalal Parekh Marg, Mumbai, Maharashtra \\ 400019
}

plants, give out high emissions and is hazardous to the environment. My Mentor Dr. Ravi Mariwala suggested the use of airlift pumps.

\section{INTRODUCTION}

The experiment was carried out by using an aquarium air pump. Four PVC pipes of the following sizes: $0.076 \mathrm{~m}, 0.15$ $\mathrm{m}, 0.23 \mathrm{~m}$, and $0.30 \mathrm{~m}$ were used. A small working model of an airlift pump was created. The objective of the first experiment was to find the rate of water ( $1 /$ minute) of the system when using $0.076 \mathrm{~m}, 0.15 \mathrm{~m}, 0.23 \mathrm{~m}$ and $0.30 \mathrm{~m}$ pipes and hence discover the underlying trend linking the flow rate to the height of the pipe. This experiment served its purpose. Using the results, it was concluded that the greater the height of the pipe the greater the flow rate. It was derived from the experiment that as the height increased, the difference in the pressure of the water and the difference in the pressure of water and air would become greater as pressure is directly proportional to the height. [1]

Experiments were carried out to further create a working prototype. The aim of the second experiment was to find out the flow rate of water using $0.076 \mathrm{~m}, 0.15 \mathrm{~m}, 0.23 \mathrm{~m}$, and 0.30 $\mathrm{m}$ pipes when the mouth of the pipes was at different heights above the water level. It was observed during this experiment that higher the mouth of the pipe from the water level, the slower the flow rate. As the height of the mouth of the pipe from the water level increases, more pressure is required to counter the gravitational force.

Finally, a prototype was designed that was fully automated and required no human intervention in watering a plant. Two planters - a smaller one containing a plant and a larger planter which could contain the smaller planter were used. The planter containing the plant was placed inside the larger planter. The larger planter was filled with water till the rim level. The plant pot was kept on a base support such that it matched the height of the larger planter with water. The purpose was to use renewable energy to operate the device and to automate the entire device. The device worked as per the theory and the observations were noted.

The final circuit consisted of solar panel connected to the charge controller to battery to inverter to timer and finally to airlift pump. After obtaining all the required components, the circuit was set up to form a working prototype.

\section{TEST BED AND EXPERIMENTAL RESULTS}

A series of experiments were carried out to collect enough data. The purpose of the first experiment was to find out how the flow rate of water changes as the height of the pipe changes. To conduct this experiment, apparatus was set up as shown in the picture below (see figure 1). An airlift pump is basically created when air is forcefully released inside a PVC pipe while it is completely submerged in water. 


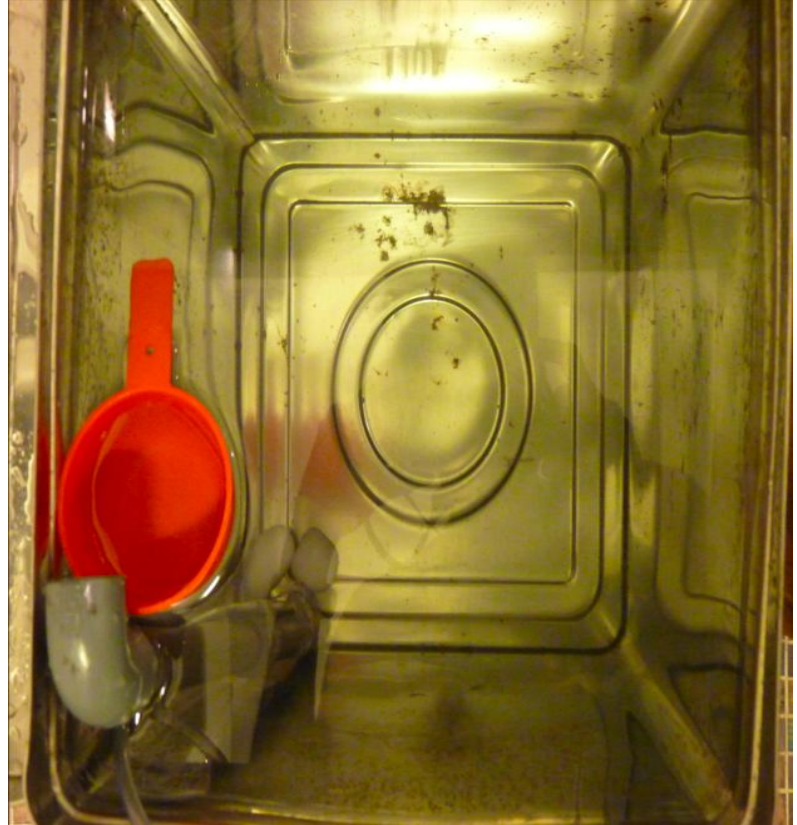

Figure 1

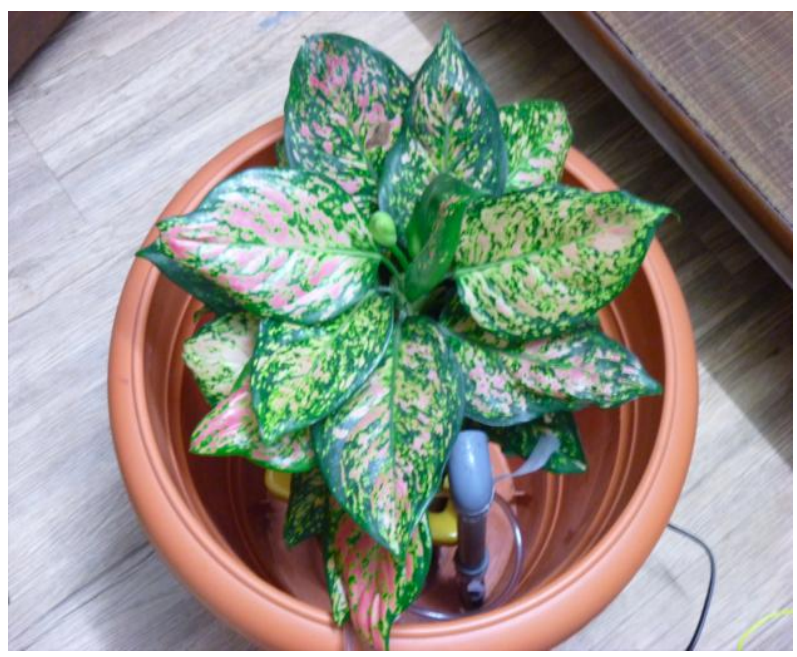

Figure 2

A100ml-measuring cup was used to collect the water. The results were as follows.

Table 1: When the length of the pipe is altered and the time taken to fill a 100ml-measuring cup is recorded

\begin{tabular}{|l|l|l|}
\hline Pipe/m & Average Time/s & Flow Rate/l/minute \\
\hline 0.0762 & $6.302 \pm 0.848$ & 0.952 \\
\hline 0.1524 & $2.408 \pm 0.378$ & 2.492 \\
\hline 0.2286 & $1.280 \pm 0.13$ & 4.688 \\
\hline 0.3048 & $1.258 \pm 0.072$ & 4.769 \\
\hline
\end{tabular}

The flow rate for this particular experiment can be calculated by dividing the volume (in liters) by the Average time taken to fill the measuring the cup. Using this data a graph can be plotted showing the relation between the pipe length and the flow rate (See figure 3).

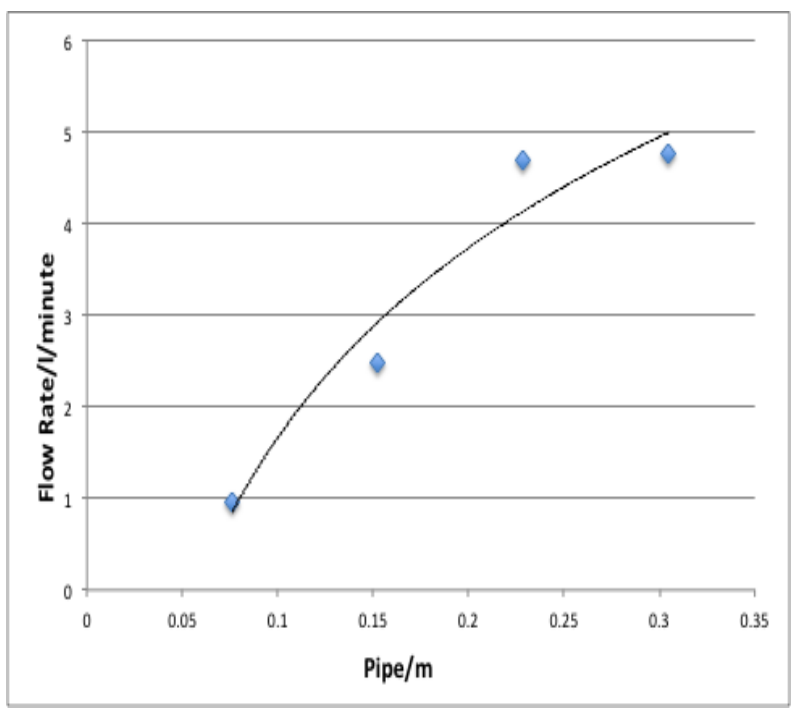

Figure 3

The graph of observations made during the experiment is given above. There was scope for human error made while filling water in the container, as it is impossible to avoid parallax error. A few air bubbles escaped from outside the pipe reducing the efficiency of the system. If the tapes holding the pipe or the air tube come loose, then the efficiency of the system could be compromised. [1]

The results plotted on the graph shows the relationship between the flow rate and the height of the pipe. It was observed that as the height of the pipe increased, so did the flow rate. However, as the height of the pipe increased from $0.23 \mathrm{~m}$ to $0.30 \mathrm{~m}$, the increase in flow rate of water had reduced. This can be seen on the graph as a slightly flatter curve towards the end.

When using the $0.30 \mathrm{~m}$ pipe it was observed that the flow rate was $4.769 \mathrm{l} /$ minute, showing that it was extremely efficient.

Although the $0.30 \mathrm{~m}$ pipe had the greatest flow rate, the $0.23 \mathrm{~m}$ pipe had a relatively similar flow rate. Therefore, for practical reasons and to avoid taking up space, it was decided to use the $0.23 \mathrm{~m}$ pump.

Following the results that were obtained from the first experiment, another experiment was carried out. The results obtained from this experiment were extremely important, and were directly implemented in the design of the final prototype. The aim of this experiment was to find out the relation between the flow rate and the height of the pipe above the water level. The same apparatus was set up as the first experiment as shown in the picture. The difference was the height of the pipe, which was different for each trial.

The entire experiment was carried out with the $0.08 \mathrm{~m}, 0.15 \mathrm{~m}$, and the $0.23 \mathrm{~m}$ pipes. It was decided not to conduct this experiment with the $0.30 \mathrm{~m}$ pipe as it had been eliminated after the first experiment. The result of this experiment was as follows: 
Table 2: 0.23m Pipe

\begin{tabular}{|l|l|l|}
\hline $\begin{array}{l}\text { HEIGHT OF } \\
\text { PIPE ABOVE } \\
\text { WATER } \\
\text { LEVEL/m }\end{array}$ & TIME TAKEN/s & $\begin{array}{l}\text { FLOW } \\
\text { RATE/l/minute }\end{array}$ \\
\hline 0.05 & 27.10 & 1.77 \\
\hline 0.10 & 56.68 & 0.85 \\
\hline 0.15 & $167: 68$ & 0.29 \\
\hline 0.20 & $350: 69$ & 0.13 \\
\hline 0.25 & -- & -- \\
\hline
\end{tabular}

Table 3: 0.08m Pipe

\begin{tabular}{|l|l|l|}
\hline $\begin{array}{l}\text { HEIGHT OF } \\
\text { PIPE ABOVE } \\
\text { WATER } \\
\text { LEVEL/m }\end{array}$ & TIME TAKEN/s & $\begin{array}{l}\text { FLOW } \\
\text { RATE/l/minute }\end{array}$ \\
\hline 0.05 & 63.58 & 0.75 \\
\hline 0.10 & 92.74 & 0.52 \\
\hline 0.15 & -- & -- \\
\hline 0.20 & -- & -- \\
\hline 0.25 & -- & -- \\
\hline
\end{tabular}

Table 4: 0.15 Pipe

\begin{tabular}{|l|l|l|}
\hline $\begin{array}{l}\text { HEIGHT OF } \\
\text { PIPE ABOVE } \\
\text { WATER } \\
\text { LEVEL/m }\end{array}$ & TIME TAKEN/s & $\begin{array}{l}\text { FLOW } \\
\text { RATE/l/minute }\end{array}$ \\
\hline 0.05 & 42.33 & 1.13 \\
\hline 0.10 & 80.58 & 0.60 \\
\hline 0.15 & 250.69 & 0.19 \\
\hline 0.20 & -- & -- \\
\hline 0.25 & -- & -- \\
\hline
\end{tabular}

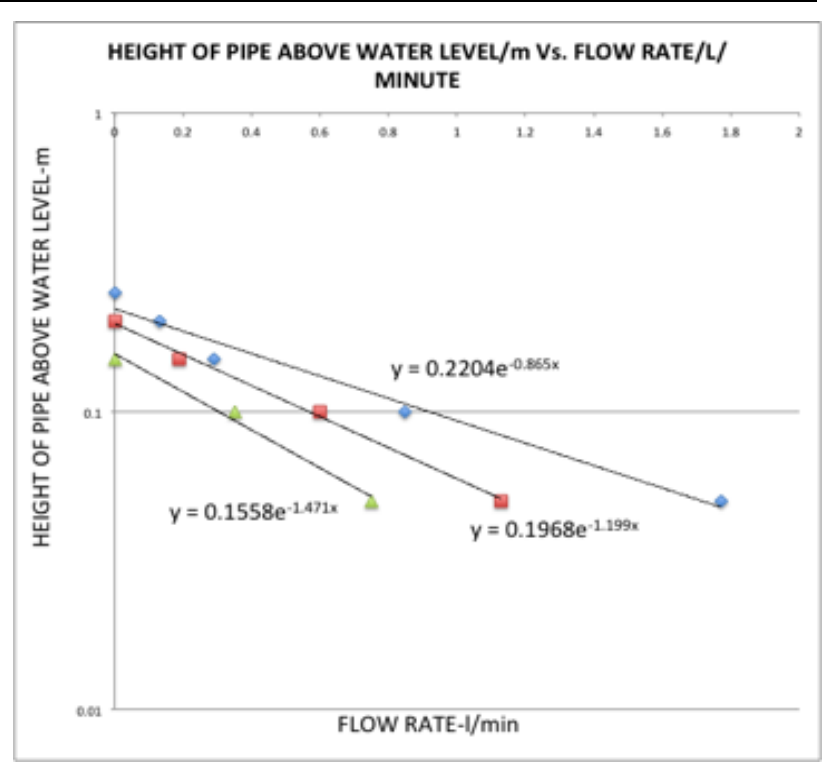

Figure 4

There were several observations that were made during the experiment. These were as follows. Few air bubbles escape from outside the pipe reducing the efficiency of the system. It was observed that when the connection of the airlift pump outlet to the PVC pipe was loose the output water flow was affected. The slug flow increased as the height above water level increased. Looking at the graph above, it was observed accurately how each of the three different pipes behaved at different heights above water level. It is obvious that the line graph on the far right is that of the $0.23 \mathrm{~m}$ pipe, in the center is the $0.15 \mathrm{~m}$ pipe, and finally on the far left is that of the $0.08 \mathrm{~m}$ pipe. The fact that all three-line graphs have the same shape and negative gradient makes the results reliable. However, it is important to note that as the height of the pipe increased the gradient of the line decreased. Most importantly the graph shows us that as height above water decreased the flow rate increased. The increased height above the water level means that the water needs to travel a greater distance. Therefore, it will require a greater force to move it against gravity. [6]

These results led to the conclusion that the two most important factors required to create a prototype was the overall height of the pipe and the height of the pipe above the water level. The final prototype was designed in great detail. A pot with a plant and a bigger empty planter were used, the holes at the bottom of the empty planter were sealed. The bigger planter was then filled with water and attached the PVC pipe and the pump as in the earlier experiments. The height of the plant pot was also measured and it was exactly $0.23 \mathrm{~m}$. A $0.01 \mathrm{~m}$ pipe was attached above the $0.23 \mathrm{~m}$ pipe and directed this towards the center of the pot. Slowly the plant pot was placed inside the empty planter with water such that the plant was supported underneath in order to match the height of the outer planter. Due to the decided height of the pipe. The PVC pipe was connected to a pump, which made the airlift pump. This was placed in the outer larger planter filled with water. Finally the switch was turned on and a slug flow was observed. This was exactly what was required by the pump. If the water flowed too fast then it would be hard to control the quantity of water being supplied. [3]

After making this prototype work using electricity, I created a circuit that would begin with the solar panel and end with the pump was designed. This was done so as to conserve electricity and use a renewable resource of energy. The components of the open loop circuit were a charge controller, a battery, an inverter, and a timer. The first three components allowed the direct current from the solar panel to be stored in the battery and converted to alternating current so that the pump that requires alternating current can use it. The timer was the final piece and allowed to automate the entire device. The timer was programmed to water the plant every morning for 30 seconds, which would provide enough water to suit the requirement of the plant. When the circuit was complete and the inverter was turned on, the solar powered airlift pump was functional and the plant was watered. (See figure 5 and Figure 6) 


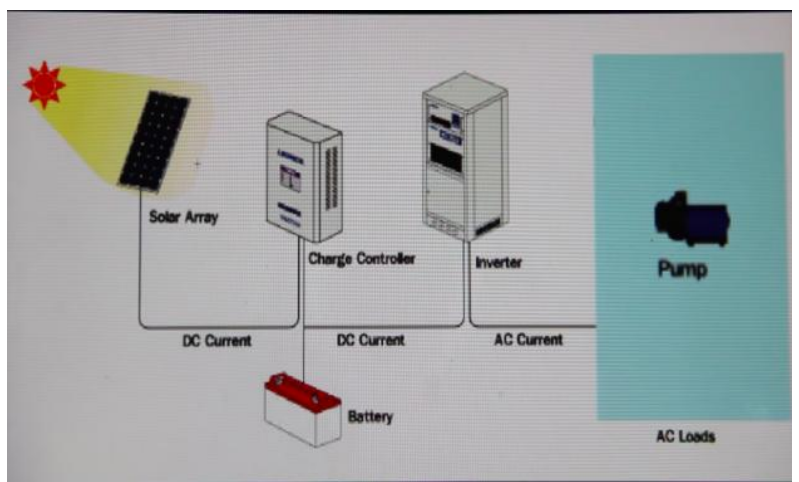

Figure 5

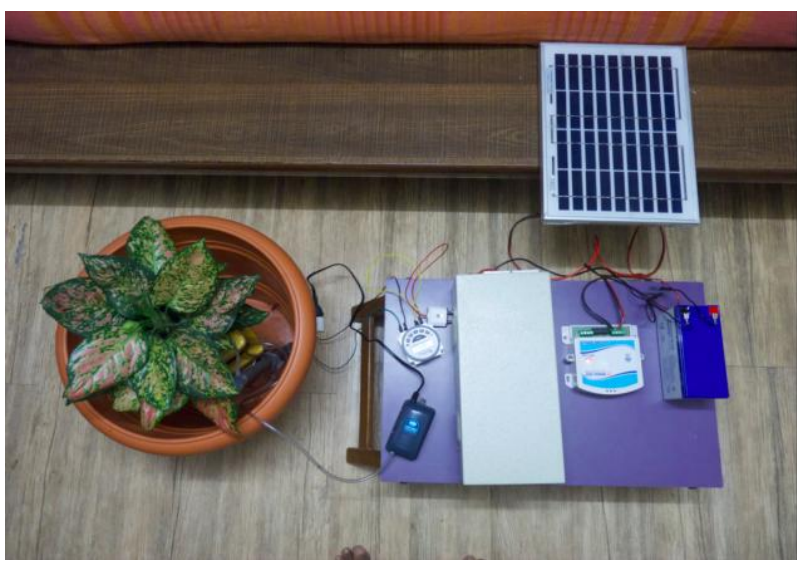

Figure 6

\section{COMERCIAL APPLICATIONS AND SOCIAL IMPLICATIONS}

Hydroponics is a subset of hydro-culture and is a method of growing plants using mineral nutrient solutions, in water, without soil. Terrestrial plants may be grown with their roots in the mineral nutrient solution only or in an inert medium, such as perlite or gravel. This is one of the foremost applications of a solar airlift pump. In a farm without any soil, the plants would require a particular amount of moisture, which could be provided by the airlift pump. The important aspect of the airlift pump in relation to this application is that the pump will allow small solid particles to also be sprinkled onto the plant and not only water. However, it can also be made to filter the water if necessary. [4]

Agriculture being the main component of the primary sector will be greatly boosted by the use of airlift pumps. In a country like India, which is primarily agricultural, the use of solar airlift pumps will help conserve electricity and use water more efficiently. There are several instances when plants are over watered and die due to this. This can be contained by using airlift pumps as the solar airlift pump is programmed to water the plants only for a certain amount of time. If the amount of water required by the plants is known, and the flow rate is known then it is easy to program the pump to run only for a particular amount of time. The airlift pump is a solar energy based machine and so is even more useful in rural corridors all over developing countries where electricity is not available.

Recirculation of water is an extremely important application of airlift pumps. It can be used in purification plants all over the world. If the outlet is fitted with a net that does not allow solid particles to pass through it, then this would be an easy substitute for primary treatment of waste. At the same time if ozone or chlorine is used instead of air to filter the waste, then they would kill most of the bacteria in the water as these two are few of the most efficient disinfectants in the worlds. This would be a cost effective replacement of the secondary treatment of waste. [4]

India is an agrarian country with around $60 \%$ of its people depending directly or indirectly upon agriculture. Farmer suicides account for $11.2 \%$ of all suicides in India. Applications such as the solar airlift pump aimed towards improving the lives of farmers who have been enjoying a less than mediocre quality of life. This application will enable the farmers to reduce manual labor and concentrate on increasing the yield of their crops.

\section{ACKNOWLEDGMENTS}

I would like to thank Dr. Sunil Karamchandani for all his guidance and support.

\section{REFERENCES}

[1] http://nenes.eas.gatech.edu/Reprints/Airlift_TC.pdf

[2] http://www.uwex.edu/uwmril/pdf/RuralEnergyIssues/aqu aculture/90_Air_Lift_Theory.pdf

[3] http://www2.ca.uky.edu/wkrec/AirliftPumps.html

[4] http://www.uwex.edu/uwmril/pdf/RuralEnergyIssues/aqu aculture/Reinemann\%20PhD\%20Thesis.pdf

[5] http://darc.cms.udel.edu/AquaPrimer/airlifts.htm

[6] http://www.prairiewaternews.ca/back/vol2no2/v22_st5.ht $\mathrm{ml}$ 